\title{
Efficiency evaluation for the heat pump system in sharp continental climate
}

\author{
Vyacheslav I. Maksimov ${ }^{1, *}$, Amer Saloum ${ }^{1}$ \\ ${ }^{1}$ National Research Tomsk Polytechnic University, 634050 Tomsk, Russia
}

\begin{abstract}
With the aim to calculate the energy efficient of water source heat pump system (HPSW) under sharp climate conditions, the ice formation processe on the surface of evaporator pipes under conditions of "autumn-winter-spring" was studied.
\end{abstract}

\section{Introduction}

The use of water bodies as energy source for heat pump system attracted the attention of researchers and engineers for many years [1-6]. A lot of heat pump systems were built in different places, but the use of these systems in Russian Federation was limited [7]. The lack of information about the water bodies temperatures and behavior in conditions of low ambient air temperatures ("autumn-winter-spring" period) is one of the main reasons of the limited using for this system.

The heating period, where the heat pump system is needed is, the cold period of the year, but when the air temperature drops under $9{ }^{\circ} \mathrm{C}$ in heating season, the water surfaces temperatures start to drop down, and the ice covers these water bodies in the central part of Russian federation in November.

When the water starts to freeze in standing reservoirs, the temperature of the surface is about $0{ }^{\circ} \mathrm{C}$, and under the surface, there is gradient in temperature to reach the value of $4{ }^{\circ} \mathrm{C}$ in a defined depth [8], where in moving water ( like in rivers the average water temperature is $1{ }^{\circ} \mathrm{C}$, and energy efficiency assessment for heat pump systems in these low temperature ranges has not been carried out up to date.

According to heat transfer principles, and the working range for the heat pump evaporator, the water will freeze on the evaporator pipe wall [9]. The efficiency analysis for heat pump system in the conditions of ice formation is recommended.

The object of this work is an experimental study for the main regularities of ice formation process on the working surfaces of evaporator pipe of HPSW, surrounded by water with average temperature $7{ }^{\circ} \mathrm{C}$, and the analysis of the main characteristics of the heat pump system with an ice-covered evaporator.

\section{The experimental research methods}

\footnotetext{
${ }^{*}$ Corresponding author: elf@tpu.ru
} 
The experimental study was done with the use of vapor compression heat pump system , the system diagram is shown in fig. 1 . The Freon 137 a was used as working refrigerant in the cycle. Refrigerant pressures in the evaporator and condenser are 0.09 , and $0.1 \mathrm{MPa}$ consequently.

The refrigerant evaporates at temperature $-30{ }^{\circ} \mathrm{C}$, and condensates at temperature $+50{ }^{\circ} \mathrm{C}$.

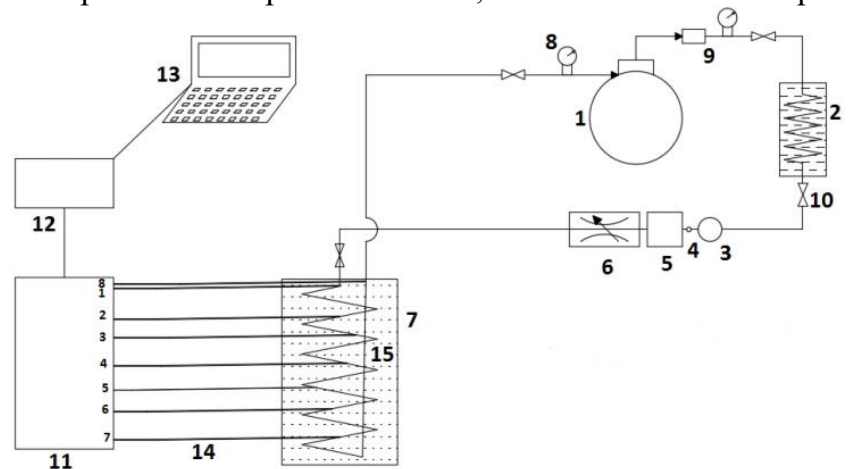

Fig1. Schematic diagram for the experiment setup: (1) - compressor; (2) - condenser. (3) - filter; (4) Sight glass; (5) - Desiccant; (6)- throttle; (7)- evaporator; (8) - Manometer; (9)- Flowmeter; (10) valve; (11) - Analog-to-digital converter; (12) - Network adapter; (13) - a computer; (14) thermocouples; (15) - water.

The dimensions of the block which contain the evaporator pipes are $0.22 \times 0.18 \times 0.25 \mathrm{~m}$, the block walls made of polypropylene with a thickness of $0.003 \mathrm{~m}$ (fig.2).

The evaporator pipe is made of copper with inner diameter $0.008 \mathrm{~m}$ and length $3.11 \mathrm{~m}$. The block was isolated with $70 \mathrm{~mm}$ thickness of foam polystyrene. The water initial temperature varies between $4.7^{\circ} \mathrm{C}$.

The average room temperature was $22^{\circ} \mathrm{C}$.

Along the experiment the fixed parameters were: the voltage, current of the compressor motor, and the refrigerant flow.

To measure the temperature along the tubes of the evaporator, 8 Chlomel-Alumel thermocouples (VIII thermocouple) with $0.1 \mathrm{~mm}$ junction size were used .The thermocouples were Connected to an analog -digital converter with a resolution of 16 bits, and an internal cold junction temperature sensor. Thermocouples were fixed with a certain pitch along the copper pipe length (Table 1), and also at different heights in the evaporator block. A network adapter was used to connect the analog -digital converter to a personal computer, and a complete galvanic isolation between the devices was provided. A software package based on the National Instruments LabVIEW was developed to register the results and measurements, special for this type of measurements [10]. The temperature values were recorded in real time with the preservation of the obtained data.

Table 1. Location of thermocouples on the surface of the pipe.

\begin{tabular}{|l|l|l|l|l|l|l|l|l|}
\hline No Thermocouple & 1 & 2 & 3 & 4 & 5 & 6 & 7 & 8 \\
\hline Pipe length L, $\mathrm{m}$ & 0 & 0.44 & 0.89 & 1.33 & 1.78 & 2.22 & 2.67 & 3.11 \\
\hline
\end{tabular}

The total relative systematic error in determining the temperature values did not exceed $4.8 \%$ over the entire range of variation of the parameters. 


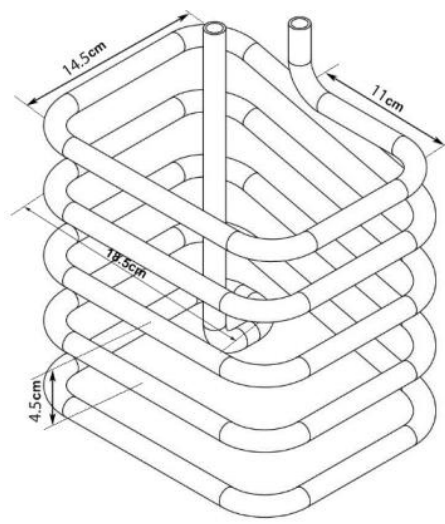

Fig2. Evaporator pipe.

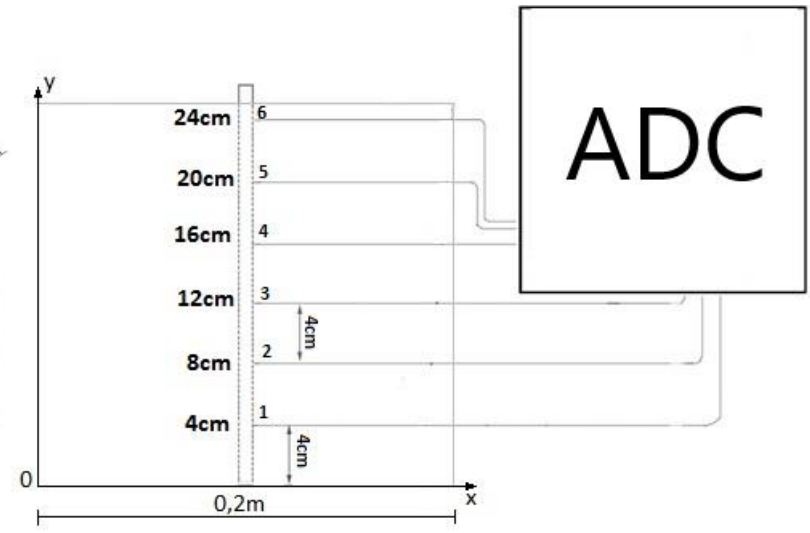

Fig3. Thermocouples location in evaporator block.

\section{The results of experimental studies}

The main experiments were carried out at a water temperature of $+7^{\circ} \mathrm{C}$ or lower. In practical practice, higher water temperatures in water bodies in the main part of the territory of Russian Federation during the heating season (October-April) are not expected .

Fig4.5 shows the values of local temperatures on the surface of the evaporator heat exchanger tube and at local points in the experimental block, measured at initial temperature of $+7^{\circ} \mathrm{C}$.

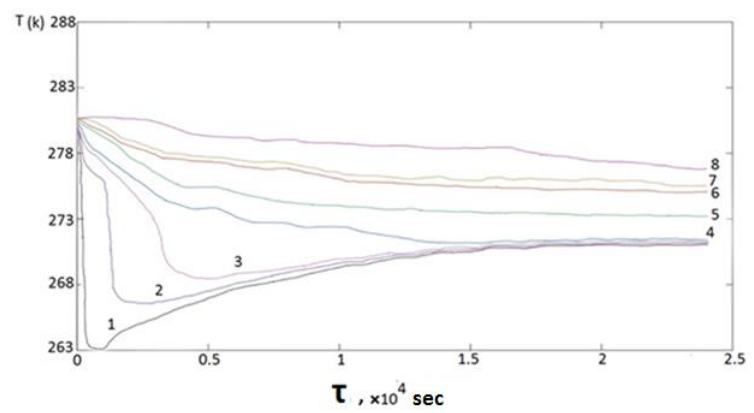

Fig 4. Temperature variation on the surface of the evaporator pipe as a function of time. (1-8) numbers of thermocouples located on the surface of the evaporator tube in accordance with Table 1.

It is noticed that after starting-up the system, a sharp drop in temperature $\mathrm{t}-10{ }^{\circ} \mathrm{C}$ occurs in the first part of the evaporator pipe (thermocouple 1-3). This is due to the fact that the main process of evaporation for the refrigerant occurs precisely in this segment of the pipe, in this section the temperatures gradually increase to $-2^{\circ} \mathrm{C}$ with the time, and on the next length of the evaporator surface the temperature smoothly decreases, the intensity of the local phase transition process decreases, and the evaporation zone expands along the length of the pipe.Temperature values were measured at different heights, in the cross section $\mathrm{X}=0.1 \mathrm{~m}$ and $0<\mathrm{Y}<0.2 \mathrm{~m}$.(Fig.3.)

In Fig. 5. It can be seen that the temperature profiles correspond to the conditions of free-convective currents in the regime under consideration. 


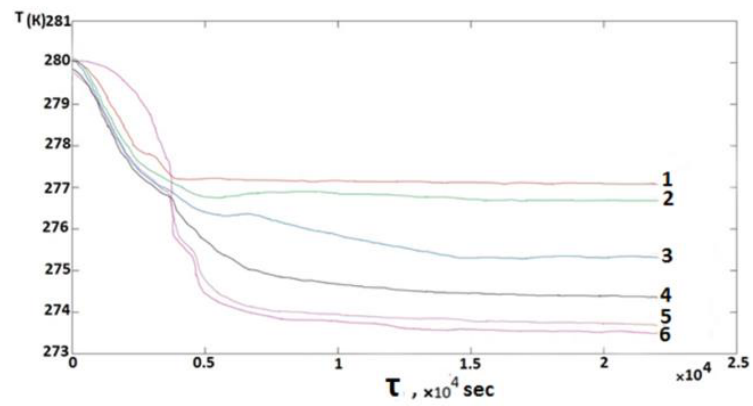

Fig 5. Dependence of water temperature on time at different points along the height of the evaporator block. $1-4 \mathrm{~cm}, 2-8 \mathrm{~cm}, 3-12 \mathrm{~cm}, 4-16 \mathrm{~cm}, 5-20 \mathrm{~cm}, 6-24 \mathrm{~cm}$.

Intensive convection currents for the studied mass of water are caused by the temperature decrease in the upper part of the heat exchanger where the intensive evaporation for the refrigerant occurs. The cooled water moves down and the warm moves up.

After $4000 \mathrm{sec}$, a sharp drop in temperature is noticed near the surface of the water, this drop is related to the fact that the when the water temperature reaches the value $4{ }^{\circ} \mathrm{C}$ the density of water becomes maximum and the warm water moves down where cold water moves up.

A smooth decrease in water temperature occurs in the studied volume, because the heat exchange becomes weaker and the temperature keeps its constant value in the first part of evaporator because of ice formation on the evaporator pipe (crystallization).

This change in the flow structure explains the change in the intensity of ice formation on the evaporator pipe (Figure 6).

The decrease in the ice formation rate on surface of the lower part of the tube after 60 minutes of operating time is due to the presence of warm water in this region. On the upper part of the pipe, the formation of ice continues with a decrease in the its rate with time, in connection with the decrease in heat transfer intensity, due to the growth of thermal resistance with the increasing of ice thickness.

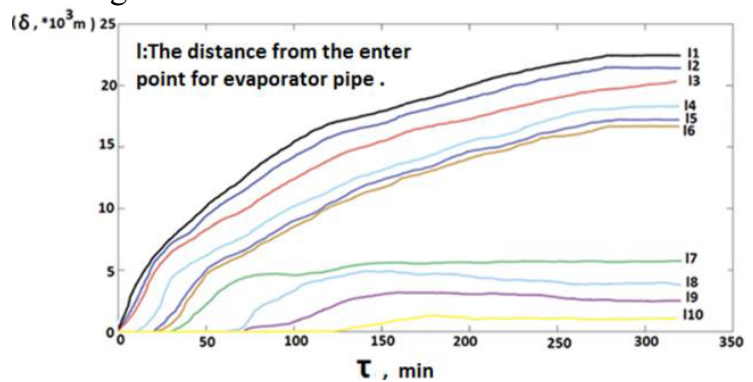

Fig 6. Dependence the ice thickness of ice along the evaporator pipe on time, (11-110) - distance along the length of the evaporator tube from the enter (Table 2).

Table 2. (11-110) are the distances along the length of the evaporator tube from the enter.

\begin{tabular}{|l|l|l|l|l|l|l|l|l|l|}
\hline $\mathbf{1 1}$ & $\mathbf{1 2}$ & $\mathbf{1 3}$ & $\mathbf{1 4}$ & $\mathbf{1 5}$ & $\mathbf{1 6}$ & $\mathbf{1 7}$ & $\mathbf{L 8}$ & $\mathbf{L 9}$ & $\mathbf{1 1 0}$ \\
\hline $0 \mathrm{~cm}$ & $4 \mathrm{~cm}$ & $10.5 \mathrm{~cm}$ & $41 \mathrm{~cm}$ & $58.5 \mathrm{~cm}$ & $63 \mathrm{~cm}$ & $96 \mathrm{~cm}$ & $119.5 \mathrm{~cm}$ & $139 \mathrm{~cm}$ & $162 \mathrm{~cm}$ \\
\hline
\end{tabular}




\section{Conclusion}

The temperatures were measured experimentally in different points in the evaporator of heat pump system, both along the surface of evaporator pipe and at different heights in the evaporator block. Also the thickness of ice on the surface of evaporator pipe were measured.

The main regularities of ice formation process on the surface of the evaporator pipe were registered depending on the working time of the HPSW.

It is noticed that the formation of ice begins on the upper part of the heat exchanger pipe, and eventually spreads down along the length of it, the depending of ice thickness along the evaporator pipe on time was registered. The influence of convective heat transfer in the evaporator chamber (heat exchanger - evaporator - water) on ice formation rate on the evaporator pipe is revealed.it can be revealed the effect of the drop in temperature under $4{ }^{\circ} \mathrm{C}$ on the nature of heat exchange process and consequently on the process of ice formation on heat exchanger surface.

The results of the research can be used to analysis the working of the heat pump system in the conditions of ice formation on evaporator wall during "autumn-spring" period in the natural water bodies, which will improve the calculation methods for the system efficiency in such conditions.

The work was supported by the Russian President's grant (Scientific School project 7538.2016.8).

\section{References}

1. Z. Shenghua, X. Xiaokai, Appl. Therm. Eng. 112, 200 (2016)

2. Y. Wang., Chongqing University, 30 (2011)

3. A. Morton, A thesis submitted in partial fulfilment for the requirement of the degree Master of Science (2013)

4. L. Nan, Q. Zhang, D. Wu, C. Zhenqian, Procedia Engineering, 121, 1880 (2016)

5. L Schibuola, M Scarpa, Energy and Buildings 113, 182 (2015)

6. N.V. Demyanovich, V.I. Maksimov, T.A. Nagornova, MATEC Web Conf. 5 (2017)

7. G.P. Vasilyeva, N.V. Peskova, V.F. Gornova, M.V. Kolesova, Geothermics 62, 93 (2016)

8. T.A.Kawalecki, A.Cybulski., Polish Academy of science, 10 (1995)

9. V. I. Maksimov, T. A. Nagornova, Vladimir. S. Chernyshev, MATEC Web Conf. 8 (2015)

10. G.V. Kuznetsov, V.I. Maksimov, J. Eng. Phys. Thermophys. 89, 1241 (2016) 